therapy apparatus is used for treating septic wounds and skin troubles met with in the industry. For a small works this apparatus is somewhat costly, but the results obtained in a relatively short time are astonishing. Treatment should be given under medical supervision.

Eyesight is of vital importance in quick and accurate production. Free eyesight tests by the visiting doctor costs the Company little and is a help to the workers. Footwear is a problem. A girl worker standing most of the day on concrete floors in thin high-heeled shoes will take very serious toll of her staying power. This is a most neglected point ; workers' footwear should be stout and in good repair. Rubber soles, except in certain types of factories, should be prohibited. The Timken Co. purchases wooden shoes (sabots) which the girls buy at half their cost to the Company. Smoking is allowed. Some works cannot do this, but where it is allowable it does help. One very strict rule, rigidly enforced, is that there must be no smoking in the half hour before people knock off; the reason for this is that fires caused by cigarette ends nearly always show within that time. Music in working hours is beneficial. The Company has had long experience of this, and broadcasts records in two sessions each day to quiet shops where work is of a monotonous nature. One class of music is given in each session-waltzes or marches ; mixing the different classes of music upsets rhythm. Vocal records are never broadcast; light classical music is broadcast at meal times. For A.R.P. shelters stirring choruses are used. Works canteens are sometimes dingy. There is no reason for this. Paint is cheap and pleasing and decorative ideas are even cheaper. A woman's ideas will soon brighten the canteen. Preparation and choice of food for the workers should be as earefully planned as the production in the factory.

\section{Control of Wild Life}

For various reasons in the national interest, a number of official decisions have recently been made to limit the numbers of certain species of British fauna, which in some cases will check the results of protective legislature and private efforts at conservation in the past decade. The Air Ministry has authorized the taking or the destruction of peregrine falcons or their eggs in certain areas including Ayrshire and Dumfriesshire in Scotland and a ten-mile deep area along the Kent and Sussex coasts in England, because of the risk of these falcons attacking carrier pigeons. A deer controller has been appointed to reduce the numbers of wild red deer in Lakeland and north Lancashire, where in recent years these animals have spread from the forest of Martindale and as a result of crossbreds with escaped hinds carted for hunting. A deer controller was appointed for a similar purpose with the Scottish deer forests last year. An Order prohibiting the use of any land for the artificial hatching and rearing of pheasants except under licence-which is chiefly granted to certain game farms where the birds are to be reared for food-does not include partridge and wild duck, but a recent inquiry by the Gamekeepers' Association to the Ministry of Agriculture elicited the information that an Order is contemplated prohibiting the rearing of all game for sporting purposes, and another prohibiting the use of feeding stuffs to game birds, except under licence. For the time being, this means the end of artificial encouragement of game birds and the complicated upsetting of the balance of Nature which it entails in the countryside.

\section{Dr. Christian Fenger}

Dr. Christran Fenger, the first teacher of pathology in the Middle West and an eminent Chicago surgeon, was born on November 2, 1840, at Copenhagen, where he qualified in 1876. He then went to Egypt, where he became a member of the Sanitary Council and surgeon to the Khalifa in the Cairo district. In the following year he settled in Chicago, where he was appointed consulting surgeon to the Cook County Hospital and lecturer on surgery to the College of Physicians and Surgeons. His postmortem examinations and surgical clinics henceforward became the centre of postgraduate instruetion in Chicago. During the thirty years of his professional life he contributed more than eighty articles to surgical literature, his chief work being connected with cancer of the stomach, hernia of the brain, the ball-valve action of floating gall-stones, the operative treatment of cerebral abscesses and the surgery of the ureters and bile-ducts. He died on March 7, 1902. After his death the Christian Fenger Memorial Association was founded under the auspices of the Chicago Medical Society and published his collected works in two large volumes.

\section{All-Electric Laundry}

ST Gabriel's LAUNDRY, of which an illustrated account is given in the Electrical Review of October 11 , is the first all-electric establishment of its kind in Eire. It serves Athlone and the surrounding region and belongs to Sisters of Mercy, one of whose main activities is the domestic training of girls. Originally all the work was done by hand, water being carried from the River Shannon. In 1907, a steam engine and washing machines were installed. Recently, the laundry has been completely electrified, resulting in greater cleanliness and better working conditions. Belt-drive and shafting have been eliminated, and there has been a consequent all-round improvement. In the new wash-house there are three large washing machines supplied directly with water at $180-200^{\circ} \mathrm{F}$., as required, from two 700-gallon storage electric water-heaters which feed the washing machine, rinsing troughs, soap boilers, starch emulsifier, etc. The water is heated at night so as to get the advantage of the cheap rate.

The utilization of electricity has greatly simplified the blueing and starching process. In the case of most of the work coming to the laundry, washing, blueing and starching processes are carried out without the clothes leaving the washing machine. Four methods of drying are available, three of them 
electrical. The drying apparatus is divided into three groups and consists of two large hydro-extractors, a drying tumbler and a drying room. The ironing room is airy, spacious, and lighted by large windows. The electric lighting is specially designed to give perfect illumination on the work and prevent glare in the eyes of the workers. Electric hand-operated irons are installed on both sides of two long tables adequately lighted from both natural and electrical sources. There are also a collar-finishing table, two large press ironers for coats, suits, etc., and one small press ironer. A calendering machine for flat work is notable by the absence of steam. The bed of the machine is electrically heated and the roller hollow and perforated. The steam which would otherwise rise when the damp articles are heated enters the roller and is drawn off by a fan through an exhaust pipe to the outside of the building.

\section{The Dionne Quintuplets}

AN editorial in the May issue of the Statistical Bulletin written on the occasion of the sixth birthday of the Dionne quintuplets on May 28 points out that never before has a similar event been recorded, as no other quintuplets have ever survived more than a few hours after birth. The five sisters, who were premature and tiny at birth, by living to the age of six have also surpassed the record of many normal full-born infants. Although about 94 per cent of all newborn baby girls live to the age of six, the chance of any group of five baby girls surviving to that age is appreciably smaller, namely, 75 per cent. At their present age each of the Dionne children has an even chance of living sixty-three years more. The editorial also points out that the Dionne quintuplets are fortunate not only in being born at a time when the knowledge of how to control sickness and death is being constantly extended, but even more so in having been attended by Dr. Dafoe, who used all the expedients of modern medical science on their behalf. As regards the special hazards to life and health facing the Dionne children in their coming year of life, the records of the Metropolitan Life Insurance Company show that accidents at the age of six are by far the greatest danger to both boys and girls. Next, but causing considerably less than half as many deaths, come influenza and pneumonia, closely followed by appendicitis, heart disease and tuberculosis.

\section{A New Museum at Leicester}

THE opening on July 23, 1940, of the Chantry House and Newarke Houses, the former dating from 1512 and the latter a century later, as a regional museum, illustrates one successful method of preserving and using characteristic examples of local architecture (Museums Journal, 40, 173; 1940). More than a quarter of a century ago these houses were threatened with destruction with a view to the erection of factories in their place; but the intervention of a few public-spirited citizens and the interest of Leicester Corporation saved the site and buildings. The new museum, to be known as the
Leicester and County Museum, is planned, according to the trust deed, "for the purpose of telling the story of the City and County of Leicester in ages past and illustrating its condition for the time being and exhibiting suggestions for its reform and improvement and the promotion and extension of artistic culture and scientific knowledge". The War has delayed the fulfiment of these projects, but a beginning has been made, and the exhibits of civic ceremonial relics, early pieces of Corporation plate, wearing apparel of the eighteenth and nineteenth centuries, military uniforms, and agricultural and domestic implements, indicate the lines on which development will proceed. At present only the ground floor is being used, but the hope is expressed that soon other parts of the buildings will contain their own special collections.

\section{Comets}

Harvard College Observatory Card 531 announces the discovery of Comet Whipple, $1933 \mathrm{f}$, by Mr. L. E. Cunningham on September 1, at Oak Ridge. Photographs made through passing clouds with the 12-inch Metcalf refractor gave the following positions :

\begin{tabular}{|c|c|c|c|c|c|c|c|}
\hline \multirow[t]{2}{*}{1940 U.T. } & \multicolumn{3}{|c|}{ R.A. $1950 \cdot 0$} & \multirow{2}{*}{\multicolumn{2}{|c|}{ Dec. }} & \multirow[t]{2}{*}{ Mag. } & \multirow[t]{2}{*}{ Diam. } \\
\hline & $\mathrm{h}$ & & $\mathrm{s}$ & & & & \\
\hline Sept. 1·1486 & 22 & 34 & $08 \cdot 1$ & $-0^{\circ}$ & $15 \cdot 9^{\prime}$ & $15 \cdot 5$ & $10^{\prime \prime}$ \\
\hline $1 \cdot 1895$ & 22 & 34 & $06 \cdot 5$ & $-0^{\circ}$ & $16 \cdot 2^{\prime}$ & $15 \cdot 1$ & \\
\hline
\end{tabular}

Perihelion passage would appear to be Jan. $22 \cdot 464$, 1941, which is about 0.23 day earlier than was predicted. The following ephemeris uses the corrected values of $T$, and gives small residuals for the above positions :

\begin{tabular}{|c|c|c|c|c|c|c|c|}
\hline \multirow[t]{2}{*}{1940 U.T. } & \multicolumn{3}{|c|}{ R.A. } & \multirow{2}{*}{\multicolumn{2}{|c|}{ Dec. }} & \multirow[t]{2}{*}{$r$} & \multirow[t]{2}{*}{$\Delta$} \\
\hline & $\mathrm{h}$ & $\mathrm{m}$ & $\mathrm{s}$ & & & & \\
\hline Nov. 3 & 22 & 24 & 30 & $6^{\circ}$ & $50 \cdot 0^{\prime}$ & $2 \cdot 538$ & $1 \cdot 955$ \\
\hline 19 & 22 & 36 & 01 & $-6^{\circ}$ & $59 \cdot 0^{\prime}$ & $2 \cdot 519$ & $2 \cdot 129$ \\
\hline Dec. 5 & 22 & 52 & 18 & $6^{\circ}$ & $26 \cdot 2^{\prime}$ & $2 \cdot 504$ & $2 \cdot 316$ \\
\hline 21 & 23 & 12 & 18 & $-5^{\circ}$ & $18 \cdot 8^{\prime}$ & $2 \cdot 494$ & $2 \cdot 505$ \\
\hline
\end{tabular}

Card 533 announces that Mr. Cunningham has found a comet on a photographic plate taken on September 5 with the 8 -inch Ross telescope at Oak Ridge. The comet appears also on eleven patrol plates taken between August 25 and September 15 at Oak Ridge or Cambridge. The estimated magnitude on August 29 was $12 \cdot 9$, but plates taken on September 9 show that the comet is slightly brighter and had a strong nucleus and a tail 2 ' long extending southward. Orbits have been computed by Cunningham and also by Maxwell and Bendler; the elements of the latter, which differ very little from those of Cunningham, are :

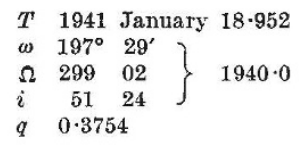

\begin{tabular}{|c|c|c|c|c|c|c|c|c|}
\hline \multicolumn{9}{|c|}{ Ephemeris $1940 \cdot 0$} \\
\hline & & & m & & & & & \\
\hline 1940 & Nov. 19 & 19 & 16 & $+35^{\circ}$ & $18^{\prime}$ & $1 \cdot 44$ & $1 \cdot 32$ & $8 \cdot 1$ \\
\hline & Dec. 21 & 19 & 18 & $20^{\circ}$ & $42^{\prime}$ & 0.76 & 0.85 & $3 \cdot 1$ \\
\hline 1941 & Jan. 22 & 19 & 59 & $-29^{\circ}$ & $06^{\prime}$ & 0.38 & 0.63 & $-2 \cdot 1$ \\
\hline & Feb. 23 & 20 & 52 & $46^{\circ}$ & $30^{\prime}$ & 0.93 & $1 \cdot 40$ & $5 \cdot 4$ \\
\hline
\end{tabular}

